\title{
Covid - 19: Morbidity Structure and Control Measures in Russia
}

\section{Lapina Elizaveta Yurievna, Puzyrev Viktor Gennadievich}

Federal State Budgetary Educational Institution of Higher Education "St. Petersburg State Pediatric Medical University" of the Ministry of Health of the Russian Federation, Russian.

\begin{abstract}
Coronaviruses are important, and used to be well known, human and animal pathogens.A novel coronavirus was identified at the end of 2019, as the cause of a number of pneumonia cases in city in the Hubei Province of China, Wuhan. Appeared to be a highly contagious anthroponotic infection. It rapidly caused an epidemic throughout China, hereafter an increasing number of cases in other countries throughout the world. All age groups, including children, are susceptible to the virus, but this age group is more likely to be asymptomatic. However, children may play a great epidemiological role in the spread of the virus with the absence of clinical signs of respiratory disease. Elderly people are the most severe carriers of the virus, as well as people with concomitant diseases. In February 2020, the World Health Organization (WHO) designated the disease COVID-19, which stands for coronavirus disease 2019. The virus that causes COVID-19 is designated severe acute respiratory syndrome coronavirus 2 (SARS-CoV-2); before, it was referred to as 2019-nCoV. We conducted meta-analysis of currently available data to summarize knowledge about the current epidemic in Russia, the dynamic of spread of the infection and management of the disease. Quarantine measures, which were carried out rather quickly, avoided the rapid spread of infection and thus contributed to a gradual increase in the load on medical facilities. As a result, most hospitals had time to prepare for an increased number of patients with coronavirus infection.
\end{abstract}

Keywords: Covid-19- Corona- Russian federation- Mortality

Asian Pac Environ Cancer, 3 (Suppl 1), 13-15

\section{Introduction}

A distinctive feature of the current pandemic, which makes it difficult to control, is the long incubation period. The advent of COVID-19 has challenged health professionals to quickly diagnose and treat patients. There is currently still limited information on epidemiology, clinical features, prevention and treatment of this disease [1]. Another negative feature is a large number of asymptomatic patients, i.e., persons who, having contracted coronavirus infection, do not demonstrate clinical manifestations, although they are capable of infecting others: in Russia their share by mid-may was about $50 \%$ on average [3-6].

The purpose of this review is to define the main steps of COVID19 spread in Russia and analyze the effectiveness of control measures.
Submission Date: 06/15/2020 Acceptance Date: 07/07/2020

\section{Results}

On 12 of May coronavirus infection has been detected in all regions of Russia. Nevertheless, Moscow and St. Petersburg account for about half of all the cases in Russia [3], which is partly due to the high population density in these cities, the high level of daily testing, as well as high tourist activity in these cities. Thus, since May 12, according to data from Johns Hopkins University [5], Russia has come second in the world by the number of infected cases. If in the world daily reveal about 80000 cases covid-19 (according to 10.05.20) [5] from them, in Russia 10000 new diseased each day, the total amount of registered cases of coronavirus infection (on 12.05.20) 232 243, among them 39801 recovered and 2009 lethal cases are revealed. Age structure of the COVID-19 in Russia: $63 \%$ were between 18 and 29 years old, $14.6 \%$

Corresponding Author:

Dr. Lapina Elizaveta Yurievna

Federal State Budgetary Educational Institution of Higher Education "St. Petersburg State Pediatric Medical University" of the Ministry of

Health of the Russian Federation, Russian.

Email: elizaveta.lap@gmail.com 
were between 30 and 49 years old, $22.4 \%$ were between 50 and 64 years old [3]. Comparing to other countries Russia has pretty unique, gradual chart of spread of COVID-19, that is the result of complex methods organized by the government from the very first cases of COVID-19 detected in Russian Federation (Figure 1). In South Korea, for example, extensive testing and isolation of patients was rapidly deployed - as a result, the number of new infections quickly declined. Another scenario is shown by the USA, where at the beginning of the outbreak there were problems with the production of tests - there the daily number of cases has only recently stabilized.

\section{Governmental measures for disease control}

One of the first steps was closing Russian-Chinese borders on January 31 , when the first two cases of coronavirus infection has been detected in Chinese citizens. A few days later air-connection was also restricted. Due to the continued spread of COVID-19 on March 11 (34 COVID-19 cases in Russia), Russian authorities for the first time began seriously restricting air traffic with the EU due to the pandemic. Moreover, they limited the admission to museums, theaters, cinemas, sport events, as well as all the restaurants and cafes were closed. On March 27 was 1000 infected, due to that, presidents announced the period from 30 March till 12 May as public quarantine and public non-working period. Since March 30 Russia has completely closed its borders: both for Russians and foreign nationals. On April 5, the number of infected exceeded 5,000 and was rapidly growing, so on $10^{\text {th }}$ of may, the number of people infected in Russia exceeded 200,000. Next day, Russia ranked third in the world, bypassing USA and Italy, but everyday gain was constantly slowing down, due to that president announced that quarantine made it possible to slow down the development of the epidemic and "significantly increase the readiness of the entire health system in case of an aggravation of the epidemiological situation" [8]. This, he said, makes it possible to start gradually lifting the restrictions. Today these measures helped to educate people to keep a distance indoors, the rules of individual prophylaxis, allowed to increase the production volume of personal protective equipment, as well as to develop and implement a system of testing for COVID-19.

\section{Laboratory examination}

Today laboratory examination for COVID-19 using methods of nucleic acid amplification is mandatory for the following categories of persons: those who returned to the Russian Federation with signs of respiratory diseases; contacted with a COVID-2019 patient; those with the diagnosis of "non - hospital pneumonia"; older than 65 years of age, who have sought medical assistance with symptoms of respiratory illness; healthcare workers with risk of infection COVID-2019 at the workplace - once a week, and in case of symptoms that do not exclude COVID-2019 - immediately; living in institutions of permanent stay regardless of the legal form of organization (special educational institutions of closed type, cadet corps, boarding houses, institutions of the Federal Service for Supervision of Health and Social Development of Russia) and the staff of such organizations - in the event of symptoms of respiratory disease.

Laboratory examination at COVID-19 is also recommended for all persons with signs of acute respiratory infection as prescribed by a medical worker [1]. Until March 16, COVID-19 tests were not scheduled for independent testing, and no tests were submitted to private medical organizations, these happened due to limited amount of test systems available. COVID-19 tests were prescribed by medical professionals in the cases mentioned above. On March 16, tests were allowed in specialized laboratories, and from March 20, mobile laboratories started working.

According to the data on 12 of May provided about 187000 tests each day, total number of tests is more than $5,6 \mathrm{mln}$ [3]. Thus, these results show that about $7 \%$ of the population has been tested, and there is still much work to be done. It should be noted that one of the problems at the moment is the long testing period, which can vary from 6 hours to 7 days, and in some cases even longer. This thus slightly increases the risk of infection spreading. According to data as of May 12, it can be noted that there has been a steady decline in the daily growth of the disease

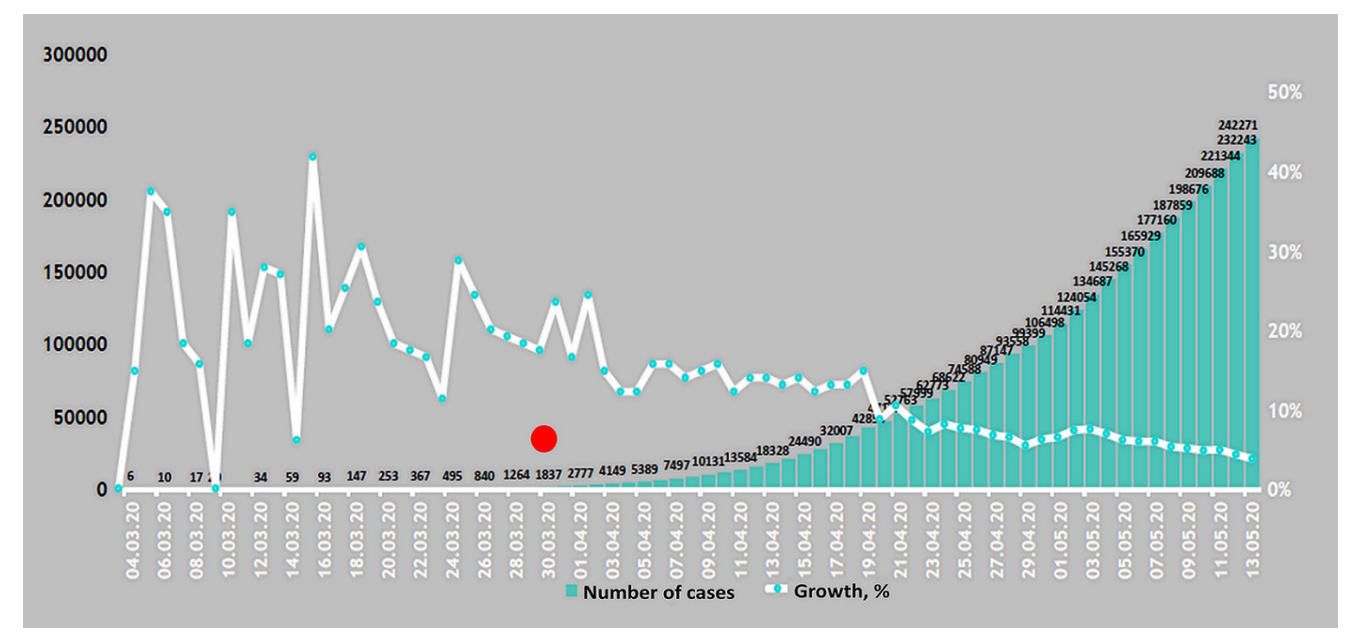

Total Number of COVID19 Cases in Russia 
in almost all regions of the country, but the incidence is still quite high.

\section{Reduction of quarantine measures}

Based on the reduction of daily gain and readiness of the health care system for the increased flow of patients at the moment (as of May 12), a gradual reduction of quarantine measures by the heads of regions is permitted in the regions. Starting from 12 of May it is allowed to gradually open some shops, parks and beauty salons. Also, many regions have introduced a strict masks regime and fines for its violation. Should be noted that in St. Petersburg and Moscow it is not yet a question of reducing quarantine measures, quarantine has been extended until May 30.

All these results would not have been possible without social support of the population, among them are: for clinically healthy persons without the possibility of isolated living, the regions of the Russian Federation have organized 489 observatories for 40,941 places, of which 284 are deployed for 28,283 places with 11,584 people; new benefits for families and children; medical certificates (sick leave) for quarantine workers; medical certificates for people older 65 y.o.; unemployment support; online marketing of drugs authorization; financial support for the disabled; financial support for tourists (flight cancellation and etc); prolongation of the documents; additional benefits for coronavirus medical workers; distant education in schools and universities.

\section{Donor plasma treatment}

One of the promising methods of treatment, which is currently being paid great attention in Russia, is donor plasma treatment. According to WHO recommendations [4], the use of pathogen reduced plasma prepared on behalf of a person with confirmed case of COVID-19 in the recovery phase to treat diseases characterized by epidemic outbreaks and lack of specific treatment is based on the concept of passive immunization. According to published data [6] plasma obtained from donors-reconvalescents of COVID-19 has been used, which is reflected in national guidelines for the treatment of COVID-19. Protocols for the clinical application of anticovide plasma to practical health care, including the definition of indications and contraindications for its use, the procedure for medical examination of the donor, and the rules of procurement, are currently being developed [1-8].

Conclusion Due to fast and strict quarantine measures, massive COVID-19 testing Russia has rather low number of COVID-19 cases. Comparing to other countries Russia has quite unique, gradual chart of COVID-19 spread, that is the result of complex methods organized by the government from the first cases of COVID-19 detected, undoubtedly had a number of difficulties, such as deficit of PPE, test-systems for COVID-19 and etc, but gradually this was fixed.

\section{References}

1. Avdeev S, Kamkin E. Temporary Methodical Recommendations for Prophylactics, Diagnostics and treatment Coronavirus Infection (COVID-19) Version 6 Moscow. 2020;13:5.

2. Avdeev S, Kamkin E. Temporary methodological recommendations for prevention, diagnosis and treatment of new coronavirus infection (COVID-19) (version 5) 02.04.2020, Moscow. 2020;:-122 C.

3. Communication Center of the Russian Government on the situation with coronavirus. "Report on the current situation with the coronavirus. Available on the resource: https:// стопкоронавирус.pф/info/ofdoc/reports/.

4. Dr Tedros Adhanom Ghebreyesus. World Health Organization. Director-General's remarks at the media briefing on 2019nCoV on 11 February 2020. WHO Director-General's remarks at the media briefing on 2019-nCoV on 11 February 2020, Accessed on February 12, 2020.

5. Johns Hopkins . University. https://coronavirus.jhu.edu/map. html 12.05.2020..

6. Rothe C, Schunk M, Sothmann P, Bretzel G, Froeschl G, Wallrauch C, Zimmer T, Thiel V, Janke C, Guggemos W, Seilmaier M, Drosten C, Vollmar P, Zwirglmaier K, Zange S, Wölfel R, Hoelscher M. Transmission of 2019-nCoV Infection from an Asymptomatic Contact in Germany. New England Journal of Medicine. 202003 05;382(10):970-971. https://doi.org/10.1056/nejmc2001468

7. To KK, Tsang OT, Leung W, Tam AR, Wu T, Lung DC, Yip CC, Cai J, Chan JM, Chik TS, Lau DP, Choi CY, Chen L, Chan W, Chan K, Ip JD, Ng AC, Poon RW, Luo C, Cheng VC, Chan JF, Hung IF, Chen Z, Chen H, Yuen K. Temporal profiles of viral load in posterior oropharyngeal saliva samples and serum antibody responses during infection by SARS-CoV-2: an observational cohort study. The Lancet Infectious Diseases. 2020 05;20(5):565-574. https://doi. org/10.1016/s1473-3099(20)30196-1

8. V.V. Putin. TV address to Russians V.V. Putin in connection with the spread of coronavirus infection 11.05.20.

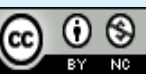

This work is licensed under a Creative Commons AttributionNon Commercial 4.0 International License. 